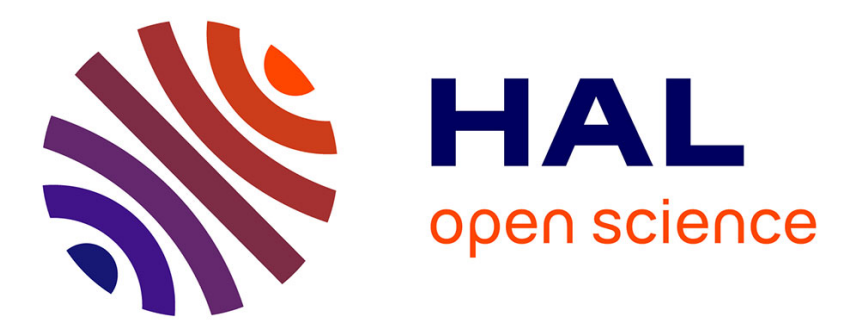

\title{
Exploring the utility of motion analysis in osteopathic clinical trials; a school-based pilot study on jaw and cervical range of motion
}

\author{
T. Bagory, P. Vaucher, H. Mhadhbi, M. Menard
}

\section{- To cite this version:}

T. Bagory, P. Vaucher, H. Mhadhbi, M. Menard. Exploring the utility of motion analysis in osteopathic clinical trials; a school-based pilot study on jaw and cervical range of motion. International Journal of Osteopathic Medicine, 2021, 41, pp.27-36. 10.1016/j.jjosm.2021.05.007 . hal-03368103

\section{HAL Id: hal-03368103 \\ https://hal.science/hal-03368103}

Submitted on 15 Oct 2021

HAL is a multi-disciplinary open access archive for the deposit and dissemination of scientific research documents, whether they are published or not. The documents may come from teaching and research institutions in France or abroad, or from public or private research centers.
L'archive ouverte pluridisciplinaire HAL, est destinée au dépôt et à la diffusion de documents scientifiques de niveau recherche, publiés ou non, émanant des établissements d'enseignement et de recherche français ou étrangers, des laboratoires publics ou privés. 


\section{Title}

Exploring the Utility of Motion Analysis in Osteopathic Clinical Trials; a School-Based Pilot Study on Jaw and Cervical Range of Motion.

Bagory T. ${ }^{1}$, Vaucher P. ${ }^{2,3}$, Mhadhbi H. ${ }^{1}$, Ménard, M. ${ }^{1,3,4}$

${ }^{1}$ Institut d'Ostéopathie de Rennes - Bretagne (IO-RB), Campus Rennes Atalante Ker-Lann, 50 rue Blaise Pascal, 35170 Bruz (France).

${ }^{2}$ Unit of Research in Mobility \& Musculoskeletal Care, School of Health Sciences Fribourg, University of Applied Sciences and Arts Western Switzerland (HES-SO), Fribourg (Switzerland).

${ }^{3}$ Clinical-Human Research Department, Nonprofit Foundation COME Collaboration, Via A. Vespucci 188, 65126, Pescara, Italy.

${ }^{4}$ Univ Rennes, M2S - EA 7470, F-35000 Rennes (France)

Corresponding author: Mathieu Ménard

Institut d'Ostéopathie de Rennes - Bretagne (IO-RB), Campus Rennes Atalante Ker-Lann 50 Rue Blaise Pascal, 35170 Bruz, France.

Mail :menard.m@io-rennes.fr 


\section{Title}

Exploring the Utility of Motion Analysis in Osteopathic Clinical Trials; a School-Based Pilot Study on Jaw and Cervical Range of Motion. 


\section{ABSTRACT}

3 Introduction: This study explores the interest of using motion analysis to evaluate cervical

4 and jaw ROM on students with or without bruxism when comparing Osteopathic

5 manipulative treatment (OMT) to sham in school settings.

6 Methods: A feasibility study was run with 48 volunteer students from an osteopathic training

7 institution. Random sequence for allocation was generated using a 1:1 ratio and block size of 8 four to either OMT or sham treatment (control group). The chosen motion outcomes of

9 interest were the lateral jaw range of motion, jaw opening, cervical rotation and side-bending.

10 ROM was measured averaging over three repeated movements at baseline, immediately after

11 the 1 st treatment, one week before the 2 nd treatment, and immediately after second treatment 12 using video-based analysis with 15 body landmarks.

13 Results: Repeated measures of joint motion at baseline showed high levels of reliability (ICC 14 ranging from 0.953 to 0.985 ). Motion analysis detected clinically important differences 15 between OMT and sham one-week post-treatment for jaw lateral ROM $\left(3.3^{\circ} ; \mathrm{p}=0.018\right)$ and 16 cervical rotation $\operatorname{ROM}\left(12.0^{\circ} ; \mathrm{p}=0.003\right)$ on participants with bruxism but not on those 17 without. Magnitude of differences were increased for all parameters following the second treatment (lateral jaw movement; $4.8^{\circ}, \mathrm{p}=0.005$; jaw opening; $5.5^{\circ}, \mathrm{p}=0.002$; cervical sidebending; $9.2^{\circ}, \mathrm{p}=0.023$; cervical rotation; $\left.18.2^{\circ}, \mathrm{p}<0.001\right)$.

Conclusion: Motion analysis is capable of detecting the effects of OMT on cervical and jaw ROM in students with bruxism but not without. Finally, the study showed the feasibility of introducing usual standards for clinical trials and sham treatment in school led studies with students.

Keywords: bruxism, osteopathic manipulative treatment, movement analysis, range of motion, cervical spine 


\section{INTRODUCTION}

\section{Background}

Bruxism is a common behaviour that is associated with several other clinical musculoskeletal symptoms (neck pain, headache, tinnitus, sleep disorders, temporomandibular pain, etc.)[1-6]. Its prevalence is similar worldwide and concerns $20 \%$ of the population, decreases with age and appears to be very common among students [7-10].

Preliminary studies have highlighted interrelations between cervical spine and jaw musculoskeletal functions [11]. Many associations supported by anatomical, physiological, biomechanical and neurophysiological studies support the idea that the musculoskeletal system of the head, the cervical spine and/or the craniocervical- mandibular system are linked [11-15]. However, other causes that regulate motion, such as central neurological processes, could be at play. Therefore, alternative approaches that address other body regions or use different approaches (ex. mindfulness, stress management, lifestyle change, etc.) could also be beneficial.

Osteopaths make a substantial contribution to primary healthcare provision to a diverse population $[16,17]$. This also includes the management of patients with bruxism and neck pain [17-20]. Osteopathy is a person-centred, primary health care discipline that often relies on touch to help to optimize, to restore, and to maintain functional balance and well-being $[21,22]$

A large debate persists in the literature about osteopathic ability to evaluate motion and dysfunction; however, most studies agree that osteopathic tests lack fidelity and accuracy [23-26]. Specific and functional tests help osteopaths to analyse and evaluate the structural and functional integrity of the body in line with critical reasoning using osteopathic principles $[25,27]$. Osteopathic motion tests remain very subjective and seem inappropriate to detect "somatic dysfunctions" as a simple dichotomous answer [24]. Pattern recognition could be the 
way clinicians use motion tests thereby making it possible to detect subtler nuances in motion.

53

54

Tests might be interpreted in a broader manner than we think and also use motion detection to detect abnormal muscular response during active self-induced polyarticular motions. Osteopathic motion tests could falsely target specific joint functions when in reality they provide information on a much more complex motion behaviour. Some behavioural pattern could reveal the intricate relationship of a whole chain of interlinked subcomponents that can only be correctly appreciated when considering motion in its entirety [28-30]. This approach for clinical interpretation is close to Johnston's concept of “bony segments as mobile units within a mobile system" [31]. His pioneering work highlighted the importance of interpreting local motion of body parts by using gross motion tests within a broader functional system [32]. Polyarticular motion could therefore help to understand dysfunction and guide treatment. This is of major importance for education and research in osteopathic healthcare $[20,33,34]$

An interesting joint to test this principle is the temporomandibular joint. Some preliminary studies have reported that osteopathic care could decrease significantly cervical spine and/or temporomandibular joint pain [35-39] even if the rationale and mechanics by which osteopathic care may decrease bruxism remains unclear. Previous authors have suggested that osteopathic care could increase spine range of motion [40-43] but few studies have focused on functional assessments on patients with bruxism. This is probably due to the difficulty in objectifying dynamic motion without impeding the movement itself [20, 44]. Detailed range of motion analysis may nevertheless help identify specific patterns of movement alterations that are not easy to identify with other means of measurement. This has now become possible with new methodologies developed in biomechanics and human movement analysis [42, 45, 46]. Video capture systems make it possible to evaluate motion in a constraint-free environment $[37,47,48]$. 
77 However, experimental observations are lacking to support the use of such analysis in clinical settings. Motion analysis is expensive, complex, and time-consuming making it difficult to apply in pragmatic clinical trials. However, the applications drawn from motion analysis could bring a better understanding of assessment procedures used in usual care and improve functional global assessment [49-53].

This study aims to investigate whether motion analysis is capable of detecting subtle changes in jaw and cervical motion in a reliable way when comparing OMT to sham therapy and identifying which outcome is best as primary outcome.

\section{METHODS}

\section{Trial design}

This study consisted of a pilot monocentric 1:1 randomised parallel trial on symptomatic and asymptomatic students. It explores the usefulness of motion analysis for future phase I and II clinical trials. Approval for this study was obtained from the institution's ethical and scientific board of XX. The study was conducted in accordance with the amended Declaration of Helsinki.

\section{Participants, randomization and allocation}

Recruitment of participants was conducted through an online questionnaire sent to all 314 students from the Institute. Answers were collected from 124 osteopathic students.

Inclusion criteria were (1) being aged between 18 and 35 years, (2) being a student at the IO$\mathrm{RB}$, (3) having no musculoskeletal disorders reported in the cervical spine or the jaw, (4) and for the bruxism group, presenting chronic bruxism for more than a year. Exclusion criteria for both groups were: (1) having dental or orthodontic treatment in progress, (2) recent tooth 

recent direct trauma.

Self-reported bruxism was not evaluated other than with the questionnaire on symptoms.

104 Symptoms related to TMJ disorders were also ruled out.

105 Participants received written and oral instructions about the intervention, test protocol, and 106 possible risks and benefits of the study. Students were told that different manual treatment approaches were to be compared without specifically mentioning one of them to be sham. This was necessary to avoid students discussing their treatment and guessing their allocation. Once data collection was over, students were informed of the true nature of both groups.

110 Written informed consent was obtained from all participants before their inclusion in the 111 study.

112 All participants agreed to avoid other forms of manual treatment during their follow-up and if 113 required to notify this protocol deviation to investigators. Participants in both group bruxism 114 or no-bruxism were randomly allocated in a 1:1 ratio to two sub-groups OMT (Treated 115 Group) or sham treatment (Control Group) using a random sequence of blocks of size 4 116 generated by R. The study flowchart is presented in Figure 1. Allocation was then attributed 117 following the order of responses to the first online questionnaire. A staff member then 118 prepared the material for the treating osteopaths. Allocation was revealed to the osteopaths on 119 the arrival of each patient when opening each folder.

\section{Interventions}

122 OMT consisted of two treatment sessions (45') separated by seven days that were 123 personalized and included patient history taking, osteopathic diagnostic assessment and OMT. 124 Participants in the treatment group were randomly allocated to one of six osteopaths with over 12510 years of practice experience. OMT was tailored for the patient by combining gentle 
techniques on areas of restriction consisting of articulatory techniques, myofascial release

127

128

129

130 techniques, functional techniques and visceral and cranial techniques, etc. The entire body was included in the osteopathic evaluation and treatment with special attention to the head, jaw and cervico-thoracic areas. Despite some expected variation in their application by different practitioners, all the techniques used were familiar to most recently trained osteopathic practitioners and taught in all French institutions.

Sham intervention (45') included patient history taking, osteopathic diagnostic assessment and two different protocols of three sham manual techniques pseudo-randomly assigned to each participant in order to reproduce, as similar as possible, the contextual variables of the sessions [54]. The sham protocol included palpation and tissue mobilisation that was predefined and targeted to specific regions without intent to change motion. All details about OMT and sham treatment interventions are reported in Table 1 using TIDieR-Placebo guidelines [55].

\section{Outcomes}

All participants were assessed four times; first at baseline, then immediately after the first session, then seven days after the first session, and finally immediately after the second session. A research team member who was not involved with the interventions and was blinded to allocations was responsible for collecting all the baseline measures and follow-up outcomes.

The chosen motion outcomes of interest were the lateral jaw range of motion, jaw opening, cervical rotation and side-bending after the 1 st and 2 nd treatment, and one week after the first treatment. This was done through a video-based system developed for this study. Participants were equipped with 15 body landmarks indexed in Figure 2. Markers trajectories were 
obtained from three sport cameras (Gopro Hero7Black, Gopro Hero6, Gopro Hero5) placed around the participant. The experimental setup was illustrated in Figure 3.

To evaluate the cervical spinal range of motion, participants were instructed to perform three trials of active maximal side-bending and rotation on each side (right and left). To evaluate

154 jaw range of motion, students were also asked to perform three trials of active open/close and right and left lateral movement of the jaw. A randomized sequence of functional active movement of cervical and jaw movement was proposed for all students. Kinovea ${ }^{\circledR}$ software (v0.8.15) was used to analyse the experimental data and to compute the range of motion of the cervical spine (side, rotation) and the temporomandibular joint (lateral and opening movement of the jaw).

\section{Blinding}

The researchers involved in the evaluation procedures had no access to the allocation of the participants. All participants were blinded to group assignment.

\section{Statistical methods}

Outliers were defined for each measure and identified. These were most often related to misreading of motion markers which had to be manually framed. Such errors were corrected. Reliability of measures was evaluated using a one-way random-effect model with absolute agreement to calculate intraclass coefficient (ICC) for individual measures before taking their mean. After verifying that the range of motion was similar between the left and right side, a single outcome was summarized by adding ROM from the left to the right side. Baseline comparison between OMT intervention group and the sham group was compared using

173 Student T-test. Linear regression was used to measure between-group differences at follow-up 174 adjusting for baseline values. All analysis were intention-to-treat. Correlation between 
175

176

177

178

179

180

181

182

183

184

185

186

187

188

189

190

191

192

193

194

195

196

197

198

outcomes was using Pearson correlation coefficients. Differences between students with or without bruxism were evaluated adding an interaction term in the logistic regression. The interaction term identified those who were both in the intervention arm and had symptoms. In other terms, the logistic regression modelled the added effects of treatment in participants with bruxism. Significance level was set at $\mathrm{p}<0.05$. No adjustments were made for multiple testing. Sensitivity analysis was done post-hoc to verify that results were consistent even after adjusting for baseline imbalance.

\section{RESULTS}

\section{Participants and baseline values}

A total of 48 participants were recruited from a $\mathrm{XX}$ osteopathic educational institution, the XX, between September and October 2019. Two participants did not attend their appointment (for medical reasons outside the context of the study) and were excluded from further analysis, resulting in a total sample of 23 participants in the bruxism group and 23 participants in the no-bruxism group. All participants received allocated treatments. No major protocol deviation was reported.

Most participants were female $(34 / 46 ; 73.9 \%)$, their age ranged from 18 to 25 years, their BMI was of 22.4 on average (ranging from 18.3 to $32.4 \mathrm{~kg} / \mathrm{m}^{2}$ ). Details on baseline values for each group are provided in Table 2. Except for cervical rotation in the group with bruxism $(\mathrm{p}=0.012)$, all other measures were well balanced between groups $(\mathrm{p}>0.05)$.

\section{Reliability}

Repeated measures of joint motion at baseline showed high levels of reliability. Individual measures had an ICC of 0.953 (CI95\% 0.925 to 0.972 ) for jaw lateral movement, an ICC of 
0.975 (CI95\% 0.959 to 0.985 ) for jaw opening, an ICC of 0.975 (CI95\% 0.959 to 0.985 ) for cervical side-bending, and an ICC of 0.985 (CI95\% 0.975 to 0.990$)$ for cervical rotation.

201

202

Objectivation of OMT on jaw lateral movement

204 One week after treatment, compared to sham, OMT treatment had a significant effect on 205 increasing lateral jaw $\mathrm{ROM}\left(+3.3^{\circ}\right.$; CI95\% 0.6 to $\left.5.9^{\circ} ; \mathrm{p}=0.018\right)$ on participants with bruxism

(Table 3). This effect was absent in the group without bruxism $\left(-0.4^{\circ}\right.$; CI95\% -2.4 to 1.7 ; $\mathrm{p}=0.720$ ). Effects of treatment were restricted to those having symptoms. Having bruxism was determinant for OMT to have effects on jaw lateral movement in the studied population (interaction test shows superiority of $4.1^{\circ}$, CI95\% 0.9 to $7.2, \mathrm{p}=0.012$ ). These results 210 remained similar even after adjustment for baseline imbalance.

211

\section{Effects on other ROMs}

213 For students with bruxism, at one week, OMT had a significant effect over sham intervention 214 on cervical rotation $\mathrm{ROM}\left(+12.0^{\circ}\right.$; $\mathrm{CI} 95 \% 4.7^{\circ}$ to $\left.19.3^{\circ}, \mathrm{p}=0.003\right)$, but not on jaw opening or 215 cervical side-bending (Table 3). Similar results were observed for short term effects, 216 immediately after the first treatment with lower magnitudes for cervical rotation $\left(+7.8^{\circ}\right.$, $217 \mathrm{p}<0.001)$ and significant effects for cervical side-bending $\left(+5.2^{\circ}, \mathrm{p}=0.045\right)$. Following the 218 second treatment, effects were significant for all parameters (Table 3).

219 For students without bruxism, compared to sham intervention, at one week there were no 220 effects on jaw opening $\left(+0.4^{\circ} ; \mathrm{p}=0.821\right)$, cervical side-bending $\left(+0.6^{\circ}, \mathrm{p}=0.851\right)$ or cervical rotation $\left(+6.4^{\circ}, \mathrm{p}=0.09\right)$. This was also the case in the short term, immediately after treatment and immediately after the second treatment except for cervical rotation which was increased by $10.4^{\circ}$ in the OMT group (CI95\% 1.7 to $10.0 ; \mathrm{p}=0.021$ ). 


\section{Correlations between parameters}

226 Changes over time at one week were correlated between jaw and cervical ROM. Students that 227 gained in lateral jaw movement also gained in cervical side-bending $(\rho=0.313, p=0.036)$ and 228 cervical rotation $(\rho=0.378, p=0.010)$. These same correlations became stronger for students with bruxism (cervical side-bending: $\rho=0.595, p=0.003$; cervical rotation: $\rho=0.440, p=0.036$ ) and optimal for cervical side-bending in students with bruxism and OMT ( $\rho=0.640, p=0.018)$. In this same sub-population, there was also a correlation between gain in cervical rotation and reduced jaw opening $(\rho=-0.567, p=0.043)$ that was however absent in other students.

\section{Efficacy of blinding}

At the 15-day follow-up, participants were asked whether they believed they were in the active or sham group. Proportion of those believing they were in the active treatment group was similar in the OMT group $(11 / 25 ; 44 \%)$ and in the sham group $(7 / 20 ; 35 \% ; \mathrm{p}=0.760)$.

Adverse events

Adverse events were monitored and self-reported one week after each treatment. No adverse events were reported by the participants.

\section{DISCUSSION}

244 The main finding of this study was that a video-based approach can objectively identify 245 effects of OMT on cervical and jaw range of motion during two sessions of osteopathic care.

246 Results showed that motion analysis made it possible to show that osteopathic manual care, as 247 compared to sham, induces increased cervical and jaw ROM. Results suggest lateral jaw movement to be a good choice for primary outcome in studies evaluating effects of OMT on 
249 patients with bruxism. This pilot study also suggests blinding to be feasible using sham 250 treatment on students. Finally, the gain in mobility was correlated between jaw lateral 251 movement and cervical side-bending supporting our initial hypothesis of the interest of 252 investigating movement over more than one joint.

253 The methodology developed in this study allowed to observe and analyse, through different 254 time intervals measurements, the effect of the osteopathic manual care over time in an 255 outstanding reliable way (ICC >0.95). The consistency of results over-time also suggests that treatment effects are conserved over at least seven days and could be emphasized by a second treatment session (Figure 4). Contrary to clinical motion tests, motion analysis can be an efficient and objective way to evaluate functional changes in movement following osteopathic manual care.

However, our results should be interpreted with caution. Joint range of motion is by no means the only mechanism involved in bruxism and several etiological factors (psychosocial, anatomical, and/or neuromuscular factors) also need to be explored during patient management. Improved range of motion may be simply a surrogate of improved motor control. Functional motion disorders have been shown to be closely related to alteration of motor control, reduced discriminatory sensation, catastrophization, fear-avoidance, and loss of self-confidence [56-58].

However, even if our results support the hypothesis that OMT could alter motor control during movement, they do not make it possible to know whether these changes represent any meaningful change for patients (i.e. reduced jaw tension, reduced pain). Range of motion often investigates movements that are most often not done naturally. The underlying

271 theoretical construct linking range of motion with daily symptoms infers that the underlying 272 changes also affect movement before reaching physiological limits. This assumption was not 273 tested. This would require collecting more descriptive and tangible evidences of individual 
motor behaviours, not only in a traditional structural model of articular dysfunction but during specific functional motion tests [26]. Also, additional determinants could be explored during functional motion-tests both with instrumental approaches (electromyography - jaw muscle activity) and non-instrumental approaches (self-reported - perceived pain, stress levels and 278 impact on daily life).

279

Practical applications for education and research

281 One of the challenges of education is to find a way to facilitate the transition from academic learning to training for their future profession but also to research [59]. Biomechanics has been introduced as an official teaching unit in the education of osteopathic students since 2014 in France [60]. The challenge is to apply both anatomical/physiological bases and mechanical concepts (mathematics and physics) to observe/describe/measure human movement from a number of different applications that cut across the sub-areas of movement sciences (sport, ergonomics, injury, clinical rehabilitation, etc.) [61, 62]. Additionally, new teaching innovative methodologies to evaluate human movement (Wii Balance Board platform, Kinect, smartphone applications, etc.) were proposed to facilitate the comprehension of biomechanics laws/applications and to make it more "touchable" and inform students about these tools and their limits $[63,64]$. The challenge is also to educate future osteopaths in the use of objective tools to evaluate their treatments in order to promote research in osteopathy and to transfer knowledge to education and clinical practice $[20,65$,

294 66]. In this sense, a large number of research themes must be proposed involving students and educators to continue building evidence by validating or disproving the knowledge or beliefs related to osteopathic care [3-6, 34]. Future challenges for the profession are to develop collaborations with other disciplines to create new knowledge and the assessment of the effectiveness of osteopathic manual care in the light of scientific methods but also to associate 
applied biomechanics and neurosciences to propose new findings in the impact of osteopathic healthcare $[34,67]$.

301

302

\section{Limitations}

303 This study involved a modest cohort of 46 students (divided into 4 experimental groups), it would be interesting for future phase 2 and 3 clinical trials to use a similar methodology measuring ROM on a larger population with a follow-up by combining, it with other measurement tools (Patient Reported Outcome Measures, validated questionnaires, electromyography, etc.) to assess the impact of the global effect of osteopathic care on 308 behaviour.

309 The study also might be limited in external validity given it targets a specific population 310 particularly concerned by bruxism [7, 9, 10]. Slight differences in treatment approaches

311 between osteopaths cannot be ruled out. All six osteopaths however work in the same school

312 clinic and are used to follow similar approaches. Nevertheless, future studies need to consider 313 training osteopaths to assure they deliver similar treatments and include fidelity analysis to 314 verify if treatment was delivered as planned. Even if blinding was assured, the students' response to treatment could be influenced by their familiarity with the discipline and 316 communication between students.

317 We collected motion with three sport cameras but not really in 3D with an optoelectronic 318 system for example. However, after comparing the data from this study with previous authors

319 who have established an important database on cervical and mandibular kinematics from 22 experimental studies using recognized systems, it appears that the data obtained are close to the standards they established $[68,69]$. In this way, we observed in this pilot study, the effect of OMT only in maximal ROM which focuses on assessing the patient's maximum capacity to perform selected active movements. In order to assess dynamic functional behaviour, it could 
324 be useful to track/estimate all the 3D kinematic of each degree of freedom to explore the

325

326 evolution of the pattern of motion during the functional assessment before and after OMT. This appears to be a better way to explore motion behaviour which is used for the quantified analysis of walking, running or rowing for example [70-73]. A potential limitation to future use of motion analysis in clinical trials is the availability and access to sophisticated material and skilled personnel making it possible to acquire meaningful data. Therefore, future studies with optoelectronic, medical system imagery or inertial sensors are needed to go further with the data collection/analysis but also to confirm the benefits of the treatment and the assessment method [74-77]. Finally, the subjectivity of active voluntary movements could have introduced social desirability bias to the observed improvements in ROM due to OMT. New insights on interoceptive perception and the eventual role of osteopathic care in helping solve misrepresentation of one's body perception and movement are promising to the profession $[67,78]$.

\section{CONCLUSION}

This study highlighted that a video-based approach may allow analysing musculoskeletal function of the jaw and cervical spine before and after OMT. Motion analysis can reveal improvements of cervical and jaw ROM following OMT in osteopathic students with bruxism compared to sham treatment. A longitudinal investigation with a larger sample is needed to confirm the benefits of the treatment and the assessment method. These outcomes are promising for future studies investigating the role of osteopathic care in preventing musculoskeletal conditions in people with bruxism.

This approach could be implemented as an additional tool to objectify the effect of osteopathic healthcare and also to the global advancement of the profession in thriving, growing osteopathic research culture necessary in the contemporary health care landscape. 
349

350

351 
353

354

355

356

357

358

359

360

361

362

363

364

365

366

367

368

369

370

371

372

373

374

375

376

377

378

379

380

381

382

383

384

385

386

387

388

389

390

391

392

393

394

395

396

397

[1] Lobbezoo, F.; Ahlberg, J.; Glaros, A. G.; Kato, T.; Koyano, K.; Lavigne, G. J.; de Leeuw, R.; Manfredini, D.; Svensson, P.; Winocur, E. Bruxism Defined and Graded: An International Consensus. J. Oral Rehabil., 2013, 40 (1), 2-4. https://doi.org/10.1111/joor.12011.

[2] Lobbezoo, F.; Ahlberg, J.; Raphael, K. G.; Wetselaar, P.; Glaros, A. G.; Kato, T.; Santiago, V.; Winocur, E.; De Laat, A.; De Leeuw, R.; et al. International Consensus on the Assessment of Bruxism: Report of a Work in Progress. J. Oral Rehabil., 2018, 45 (11), 837-844. https://doi.org/10.1111/joor.12663.

[3] Martinot, J.-B.; Borel, J.-C.; Le-Dong, N.-N.; Silkoff, P. E.; Denison, S.; Gozal, D.; Pépin, J.-L. Bruxism Relieved Under CPAP Treatment in a Patient With OSA Syndrome. Chest, 2020, 157 (3), e59-e62. https://doi.org/10.1016/j.chest.2019.07.032.

[4] Martynowicz, H.; Smardz, J.; Michalek-Zrabkowska, M.; Gac, P.; Poreba, R.; Wojakowska, A.; Mazur, G.; Wieckiewicz, M. Evaluation of Relationship Between Sleep Bruxism and Headache Impact Test-6 (HIT-6) Scores: A Polysomnographic Study. Front. Neurol., 2019, 10. https://doi.org/10.3389/fneur.2019.00487.

[5] Ohlmann, B.; Waldecker, M.; Leckel, M.; Bömicke, W.; Behnisch, R.; Rammelsberg, P.; Schmitter, M. Correlations between Sleep Bruxism and Temporomandibular Disorders. J. Clin. Med., 2020, 9 (2), 611. https://doi.org/10.3390/jcm9020611.

[6] Yap, A. U.; Chua, A. P. Sleep Bruxism: Current Knowledge and Contemporary Management. J. Conserv. Dent. JCD, 2016, 19 (5), 383-389. https://doi.org/10.4103/0972-0707.190007.

[7] Cavallo, P.; Carpinelli, L.; Savarese, G. Perceived Stress and Bruxism in University Students. BMC Res. Notes, 2016, 9 (1), 514. https://doi.org/10.1186/s13104-016-2311-0.

[8] Manfredini, D.; Winocur, E.; Guarda-Nardini, L.; Paesani, D.; Lobbezoo, F. Epidemiology of Bruxism in Adults: A Systematic Review of the Literature. J. Orofac. Pain, 2013, 27 (2), 99110. https://doi.org/10.11607/jop.921.

[9] Soares, L. G.; Costa, I. R.; Júnior, J. dos S. B.; Cerqueira, W. S. B.; Oliveira, E. S. de; Oliveira, D. W. D. de; Gonçalves, P. F.; Glória, J. C. R.; Tavano, K. T. A.; Flecha, O. D. Prevalence of Bruxism in Undergraduate Students. CRANIO®, 2017, 35 (5), 298-303. https://doi.org/10.1080/08869634.2016.1218671.

[10] Wetselaar, P.; Vermaire, E. (J H. ); Lobbezoo, F.; Schuller, A. A. The Prevalence of Awake Bruxism and Sleep Bruxism in the Dutch Adult Population. J. Oral Rehabil., 2019, 46 (7), $617-$ 623. https://doi.org/10.1111/joor.12787.

[11] Gouw, S.; Frowein, A.; Braem, C.; Wijer, A. de; Creugers, N. H. J.; Pasman, J. W.; Doorduin, J.; Kalaykova, S. I. Coherence of Jaw and Neck Muscle Activity during Sleep Bruxism. J. Oral Rehabil., 2020, 47 (4), 432-440. https://doi.org/10.1111/joor.12932.

[12] Armijo Olivo, S.; Magee, D. J.; Parfitt, M.; Major, P.; Thie, N. M. R. The Association between the Cervical Spine, the Stomatognathic System, and Craniofacial Pain: A Critical Review. $J$. Orofac. Pain, 2006, 20 (4), 271-287.

[13] Armijo-Olivo, S.; Magee, D. Cervical Musculoskeletal Impairments and Temporomandibular Disorders. J. Oral Maxillofac. Res., 2013, 3 (4). https://doi.org/10.5037/jomr.2012.3404.

[14] Olivo, S. A.; Fuentes, J.; Major, P. W.; Warren, S.; Thie, N. M. R.; Magee, D. J. The Association between Neck Disability and Jaw Disability. J. Oral Rehabil., 2010, 37 (9), 670-679. https://doi.org/10.1111/j.1365-2842.2010.02098.x.

[15] Piekartz, H. von; Rösner, C.; Batz, A.; Hall, T.; Ballenberger, N. Bruxism, Temporomandibular Dysfunction and Cervical Impairments in Females - Results from an Observational Study. Musculoskelet. Sci. Pract., 2020, 45, 102073. https://doi.org/10.1016/j.msksp.2019.102073. 
401

402

403

404

405

406

407

408

409

410

411

412

413

414

415

416

417

418

419

420

421

422

423

424

425

426

427

428

429

430

431

432

433

434

435

436

437

438

439

440

441

442

443

[16] Thomson, O. P.; Petty, N. J.; Moore, A. P. Osteopaths' Professional Views, Identities and Conceptions - A Qualitative Grounded Theory Study. Int. J. Osteopath. Med., 2014, 17 (3), 146-159. https://doi.org/10.1016/j.ijosm.2013.12.002.

[17] Vaucher, P.; Macdonald, R. J. D.; Carnes, D. The Role of Osteopathy in the Swiss Primary Health Care System: A Practice Review. BMJ Open, 2018, 8 (8). https://doi.org/10.1136/bmjopen-2018-023770.

[18] Bill, A.-S.; Dubois, J.; Pasquier, J.; Burnand, B.; Rodondi, P.-Y. Osteopathy in the FrenchSpeaking Part of Switzerland: Practitioners' Profile and Scope of Back Pain Management. PLOS ONE, 2020, 15 (5), e0232607. https://doi.org/10.1371/journal.pone.0232607.

[19] Morin, C.; Aubin, A. Primary Reasons for Osteopathic Consultation: A Prospective Survey in Quebec. PLoS One, 2014, 9 (9), e106259. https://doi.org/10.1371/journal.pone.0106259.

[20] Steel, A.; Foley, H.; Redmond, R. Person-Centred Care and Traditional Philosophies in the Evolution of Osteopathic Models and Theoretical Frameworks: Response to Esteves et Al. Int. J. Osteopath. Med., 2020, $O$ (0). https://doi.org/10.1016/j.ijosm.2020.03.001.

[21] OIA. Osteopathy and Osteopathic Practice; A Global View of Practice, Patients, Education and the Contribution to Healthcare Delivery; Osteopathic International Alliance: Chicago, 2013.

[22] World Health Organisation. Benchmarks for Training in Traditional /Complementary and Alternative Medicine: Benchmarks for Training in Osteopathy; WHO: Geneva, 2010.

[23] Basile, F.; Scionti, R.; Petracca, M. Diagnostic Reliability of Osteopathic Tests: A Systematic Review. Int. J. Osteopath. Med., 2017, 25, 21-29. https://doi.org/10.1016/j.ijosm.2017.03.004.

[24] Fryer, G. Somatic Dysfunction: An Osteopathic Conundrum. Int. J. Osteopath. Med., 2016, 22, 52-63. https://doi.org/10.1016/j.ijosm.2016.02.002.

[25] Vaucher, P. Questioning the Rationality of Clinical Osteopathic Tests : Future Perspectives for Research. Mains Libr., 2016, 33 (1), 33-37.

[26] Johnston, W. L.; Vorro, J. A Call for Osteopathic Descriptive Research: Use of a Functional Model to Distinguish Segmental Motion Behavior. J. Osteopath. Med., 2003, 6 (1), 30-33. https://doi.org/10.1016/S1443-8461(03)80007-2.

[27] DiGiovanna, E. L.; Schiowitz, S.; Dowling, D. J. An Osteopathic Approach to Diagnosis and Treatment; Lippincott Williams \& Wilkins, 2005.

[28] Chenaut, P.; Ménard, M.; Vaucher, P.; Lancelot, L.; Bideau, B.; Bourgin, M. Biomechanical Analysis of the Lumbar-Pelvic-Femoral Complex during the One- Sided Tilt Test: A Pilot Study in Triathletes. Comput. Methods Biomech. Biomed. Engin., 2019, 22, S1-S393. https://doi.org/10.1080/10255842.2020.1714921.

[29] Ménard, M.; Vaucher, P.; Chenaut, P.; Lancelot, L.; Francois, L.; Bourgin, M.; Bideau, B. Analyse biomécanique du complexe lombo-pelvi- fémoral lors du test d'inclinaison unilatérale du bassin : étude pilote sur des triathlètes. Mains Libr., 2019, No. 3, 19-26.

[30] Retailleau, M.; Colloud, F. New Insights into Lumbar Flexion Tests Based on Inverse and Direct Kinematic Musculoskeletal Modeling. J. Biomech., 2020, 109782. https://doi.org/10.1016/j.jbiomech.2020.109782.

[31] Johnston, W. Functional Methods; American Academy Osteopathy: Indianapolis, Ind., 2004.

[32] Osteopathy, A. A. of; and clinical investigator. The Johnston Academy Yearbook honors William L. Johnston, D. O. Scientific Contributions of William L. Johnston, DO, FAAO; FAAO Myron C. Beal, D. O., Ed.; Indianapolis, IN., 1998.

[33] Esteves, J. E.; Zegarra-Parodi, R.; van Dun, P.; Cerritelli, F.; Vaucher, P. Models and Theoretical Frameworks for Osteopathic Care - A Critical View and Call for Updates and Research. Int. J. Osteopath. Med., 2020, 35, 1-4. https://doi.org/10.1016/j.ijosm.2020.01.003. 
[34] Ménard, M.; Draper-Rodi, J.; Merdy, O.; Wagner, A.; Tavernier, P.; Jacquot, E.; Mhadhbi, H. Finding a Way between Osteopathic Principles and Evidence-Based Practices: Response to Esteves et Al. Int. J. Osteopath. Med., 2020, S1746068920301383. https://doi.org/10.1016/j.ijosm.2020.07.006.

[35] Cuccia, A. M.; Caradonna, C.; Annunziata, V.; Caradonna, D. Osteopathic Manual Therapy versus Conventional Conservative Therapy in the Treatment of Temporomandibular Disorders: A Randomized Controlled Trial. J. Bodyw. Mov. Ther., 2010, 14 (2), 179-184. https://doi.org/10.1016/j.jbmt.2009.08.002.

[36] Gesslbauer, C.; Vavti, N.; Keilani, M.; Mickel, M.; Crevenna, R. Effectiveness of Osteopathic Manipulative Treatment versus Osteopathy in the Cranial Field in Temporomandibular Disorders - a Pilot Study. Disabil. Rehabil., 2018, 40 (6), 631-636. https://doi.org/10.1080/09638288.2016.1269368.

[37] Manzotti, A.; Viganoni, C.; Lauritano, D.; Bernasconi, S.; Paparo, A.; Risso, R.; Nanussi, A. Evaluation of the Stomatognathic System before and after Osteopathic Manipulative Treatment in 120 Healthy People by Using Surface Electromyography. Int. J. Environ. Res. Public. Health, 2020, 17 (9), 3250. https://doi.org/10.3390/ijerph17093250.

[38] Monaco, A.; Cozzolino, V.; Cattaneo, R.; Cutilli, T.; Spadaro, A. Osteopathic Manipulative Treatment (OMT) Effects on Mandibular Kinetics: Kinesiographic Study. Eur. J. Paediatr. Dent., 2008, 6.

[39] Burns, D. K.; Wells, M. R. Gross Range of Motion in the Cervical Spine: The Effects of Osteopathic Muscle Energy Technique in Asymptomatic Subjects. JAOA, 2006, 106 (3), 6.

[40] Branney, J.; Breen, A. C. Does Inter-Vertebral Range of Motion Increase after Spinal Manipulation? A Prospective Cohort Study. Chiropr. Man. Ther., 2014, 22 (1), 24. https://doi.org/10.1186/s12998-014-0024-9.

[41] Fryer, G.; Ruszkowski, W. The Influence of Contraction Duration in Muscle Energy Technique Applied to the Atlanto-Axial Joint. J. Osteopath. Med., 2004, 7 (2), 79-84. https://doi.org/10.1016/S1443-8461(04)80016-9.

[42] Ménard, M.; Vaucher, P.; Mhadhbi, H.; Bideau, B.; Bourgin, M. Modélisation du système musculo-squelettique : Implications cliniques, prévention des blessures et perspectives pour la recherche en ostéopathie. Neurophysiol. Clin., 2019, 49 (3), 258. https://doi.org/10.1016/j.neucli.2019.01.024.

[43] Millan, M.; Leboeuf-Yde, C.; Budgell, B.; Descarreaux, M.; Amorim, M.-A. The Effect of Spinal Manipulative Therapy on Spinal Range of Motion: A Systematic Literature Review. Chiropr. Man. Ther., 2012, 20, 23. https://doi.org/10.1186/2045-709X-20-23.

[44] Alvarez, G.; Solà, I.; Sitjà-Rabert, M.; Fort-Vanmeerhaeghe, A.; Gich, I.; Fernández, C.; Bonfill, X.; Urrútia, G. A Methodological Review Revealed That Reporting of Trials in Manual Therapy Has Not Improved over Time. J. Clin. Epidemiol., 2020, 121, 32-44. https://doi.org/10.1016/j.jclinepi.2020.01.006.

[45] Begon, M.; Lacouture, P. Modélisation Anthropométrique Pour Une Analyse Mécanique Du Geste Sportif: Partie 1 : Modèles, Leurs Caractéristiques et Leur Validation. Sci. Mot., 2005, No. 54, 11-33. https://doi.org/10.3917/sm.054.0011.

[46] Begon, M.; Lacouture, P. Modélisation Anthropométrique Pour Une Analyse Mécanique Du Geste Sportif:: Partie 2: Estimation Des Centres Articulaires et Détermination de La Cinématique Du Squelette. Sci. Mot., 2010, No. 55, 35-60. https://doi.org/10.3917/sm.055.0035.

[47] Ren, S. Biomechanical Effects of Cranio-Cervical Positions on Cervical Musculoskeletal Disorders. 2017.

[48] Salem, W. La colonne cervicale de la physiologie intersegmentaire tridimensionnelle à la manipulation ostéopathique par haute vitesse basse amplitude études in vivo. 2013. 
[49] Balsalobre-Fernández, C.; Tejero-González, C. M.; del Campo-Vecino, J.; Bavaresco, N. The Concurrent Validity and Reliability of a Low-Cost, High-Speed Camera-Based Method for Measuring the Flight Time of Vertical Jumps. J. Strength Cond. Res., 2014, 28 (2), 528-533. https://doi.org/10.1519/JSC.0b013e318299a52e.

[50] Bernardina, G. R. D.; Monnet, T.; Pinto, H. T.; Barros, R. M. L. de; Cerveri, P.; Silvatti, A. P. Are Action Sport Cameras Accurate Enough for 3D Motion Analysis? A Comparison With a Commercial Motion Capture System. J. Appl. Biomech., 2017, 35 (1), 80-86. https://doi.org/10.1123/jab.2017-0101.

[51] Elwardany, S. H.; El-Sayed, W. H.; Ali, M. F. Reliability of Kinovea Computer Program in Measuring Cervical Range of Motion in Sagittal Plane. OALib, 2015, 02 (09), 1-10. https://doi.org/10.4236/oalib.1101916.

[52] Guzmán-Valdivia, C. H.; Blanco-Ortega, A.; Oliver-Salazar, M. A.; Carrera-Escobedo, J. L. Therapeutic Motion Analysis of Lower Limbs Using Kinovea. 2013, 3 (2), 7.

[53] Puig-Diví, A.; Escalona-Marfil, C.; Padullés-Riu, J. M.; Busquets, A.; Padullés-Chando, X.; Marcos-Ruiz, D. Validity and Reliability of the Kinovea Program in Obtaining Angles and Distances Using Coordinates in 4 Perspectives. PLOS ONE, 2019, 14 (6), e0216448. https://doi.org/10.1371/journal.pone.0216448.

[54] Rossettini, G.; Carlino, E.; Testa, M. Clinical Relevance of Contextual Factors as Triggers of Placebo and Nocebo Effects in Musculoskeletal Pain. BMC Musculoskelet. Disord., 2018, 19. https://doi.org/10.1186/s12891-018-1943-8.

[55] Howick, J.; Webster, R. K.; Rees, J. L.; Turner, R.; Macdonald, H.; Price, A.; Evers, A. W. M.; Bishop, F.; Collins, G. S.; Bokelmann, K.; et al. TIDieR-Placebo: A Guide and Checklist for Reporting Placebo and Sham Controls. PLOS Med., 2020, 17 (9), e1003294. https://doi.org/10.1371/journal.pmed.1003294.

[56] O'Sullivan, P. Diagnosis and Classification of Chronic Low Back Pain Disorders: Maladaptive Movement and Motor Control Impairments as Underlying Mechanism. Man. Ther., 2005, 10 (4), 242-255. https://doi.org/10.1016/j.math.2005.07.001.

[57] Wernli, K.; Tan, J.-S.; O’Sullivan, P.; Smith, A.; Campbell, A.; Kent, P. Does Movement Change When Low Back Pain Changes? A Systematic Review. J. Orthop. Sports Phys. Ther., 2020, 1-48. https://doi.org/10.2519/jospt.2020.9635.

[58] Lin, I.; Wiles, L.; Waller, R.; Caneiro, J. P.; Nagree, Y.; Straker, L.; Maher, C. G.; O’Sullivan, P. P. B. Patient-Centred Care: The Cornerstone for High-Value Musculoskeletal Pain Management. Br. J. Sports Med., 2020, 54 (21), 1240-1242. https://doi.org/10.1136/bjsports-2019-101918.

[59] Launay, F.; Ménard, M.; Bourgin, M.; Mhadhbi, H.; Sutre, F.; Draper-Rodi, J. Impact of Different Types of Revision Materials on the Learning of Musculoskeletal Techniques. Int. J. Osteopath. Med., 2020, $O$ (0). https://doi.org/10.1016/j.ijosm.2020.08.003.

[60] Décret $N^{\circ}$ 2014-1505 Du 12 Décembre 2014 Relatif à La Formation En Ostéopathie; 2014.

[61] Hamill, J. Biomechanics Curriculum: Its Content and Relevance to Movement Sciences. Quest, 2007, 59 (1), 25-33. https://doi.org/10.1080/00336297.2007.10483533.

[62] Wallace, B.; Knudson, D. The Effect of Course Format on Student Learning in Introductory Biomechanics Courses That Utilise Low-Tech Active Learning Exercises. Sports Biomech., 2020, $O$ (0), 1-10. https://doi.org/10.1080/14763141.2020.1830163.

[63] Clark, R. A.; Mentiplay, B. F.; Pua, Y.-H.; Bower, K. J. Reliability and Validity of the Wii Balance Board for Assessment of Standing Balance: A Systematic Review. Gait Posture, 2018, 61, 40-54. https://doi.org/10.1016/j.gaitpost.2017.12.022.

[64] Keogh, J. W. L.; Cox, A.; Anderson, S.; Liew, B.; Olsen, A.; Schram, B.; Furness, J. Reliability and Validity of Clinically Accessible Smartphone Applications to Measure Joint Range of 
Motion: A Systematic Review. PloS One, 2019, 14 (5), e0215806. https://doi.org/10.1371/journal.pone.0215806.

541
[65] Browning, S. Teaching Osteopathic Students Technique; Using Research to Identify Good Teaching Practice. Int. J. Osteopath. Med., 2010, 13 (2), 70-73. https://doi.org/10.1016/j.ijosm.2009.10.004.

[66] Fryer, G. Teaching Critical Thinking in Osteopathy - Integrating Craft Knowledge and Evidence-Informed Approaches. Int. J. Osteopath. Med., 2008, 11 (2), 56-61. https://doi.org/10.1016/j.ijosm.2008.02.005.

[67] Esteves, J. E.; Zegarra-Parodi, R.; Dun, P. van; Cerritelli, F.; Vaucher, P. Models and Theoretical Frameworks for Osteopathic Care - A Critical View and Call for Updates and Research. Int. J. Osteopath. Med., 2020, 35, 1-4. https://doi.org/10.1016/j.ijosm.2020.01.003.

[68] Koeppel, T. Analyse cinématique de l'appareil manducateur humain : constitution d'une base de données de sujets asymptomatiques et comparaison avec sujets à dysfonction. phdthesis, Université de Lorraine, 2017.

[69] Boussion, L. Étude cinématique tridimensionnelle du rachis cervical. Comparaison entre sujets Asymptomatiques et pathologiques. phdthesis, Université Claude Bernard - Lyon I, 2008.

[70] Chehab, E. F.; Andriacchi, T. P.; Favre, J. Speed, Age, Sex, and Body Mass Index Provide a Rigorous Basis for Comparing the Kinematic and Kinetic Profiles of the Lower Extremity during Walking. J. Biomech., 2017, 58, 11-20. https://doi.org/10.1016/j.jbiomech.2017.04.014.

[71] Ménard, M.; Sorel, A.; Boumpoutou, R.; Kulpa, R.; Kerhervé, H. A.; Bideau, B. A Musculoskeletal Modelling Approach of the Assessment of the Risk of Hamstring Injuries in Professional Soccer Players: A Pilot Study. Sci. Med. Footb., 2020. https://doi.org/10.1080/24733938.2020.1786765.

[72] Retailleau, M.; Domalain, M.; Ménard, M.; Colloud, F. Kinematics of the Lumbar Muscles in Rowing: A Preliminary Study. Comput. Methods Biomech. Biomed. Engin., 2017, 20 (sup1), 173-174. https://doi.org/10.1080/10255842.2017.1382918.

[73] Riley, P. O.; Paolini, G.; Della Croce, U.; Paylo, K. W.; Kerrigan, D. C. A Kinematic and Kinetic Comparison of Overground and Treadmill Walking in Healthy Subjects. Gait Posture, 2007, 26 (1), 17-24. https://doi.org/10.1016/j.gaitpost.2006.07.003.

[74] Cazzola, D.; Holsgrove, T. P.; Preatoni, E.; Gill, H. S.; Trewartha, G. Cervical Spine Injuries: A Whole-Body Musculoskeletal Model for the Analysis of Spinal Loading. PLOS ONE, 2017, 12 (1), e0169329. https://doi.org/10.1371/journal.pone.0169329.

[75] Plocharski, M.; Lindstroem, R.; Lindstroem, C. F.; Østergaard, L. R. Motion Analysis of the Cervical Spine during Extension and Flexion: Reliability of the Vertebral Marking Procedure. Med. Eng. Phys., 2018, 61, 81-86. https://doi.org/10.1016/j.medengphy.2018.07.010.

[76] Raya, R.; Garcia-Carmona, R.; Sanchez, C.; Urendes, E.; Ramirez, O.; Martin, A.; Otero, A. An Inexpensive and Easy to Use Cervical Range of Motion Measurement Solution Using Inertial Sensors. Sensors, 2018, 18 (8), 2582. https://doi.org/10.3390/s18082582.

[77] Salem, W.; Klein, P. In Vivo 3D Kinematics of the Cervical Spine Segments during PreManipulative Positioning at the C4/C5 Level. Man. Ther., 2013, 18 (4), 321-326. https://doi.org/10.1016/j.math.2012.11.007.

[78] Esteves, J. Predictive Processing and Allostatic Regulation in Clinical Practice. In COME to Quantum Global: Allostasis the essence of clinical practice; Catania (Italy), 2019; p 37. 
584

585

586

587

588

589

590

591

592

593

594

595

596

597

598

599

600

601

602

603

604

605

\section{FIGURES legends}

Figure 1. Flowchart of the study.

Figure 2. Diagram and anatomical localization of markers used during the study; THD: Top of head, FHD: Front of head, BHD: Back of head, FNS: Frontonasal suture, LTMJ: Left temporomandibular joint, RTMJ: Right temporomandibular joint, RGA: Right Gonial Angle, LGA: Left Gonial Angle, SIP: Superior incisive point, IIP: Inferior incisive point, RACJ: Right acromio-clavicular joint, LACJ: Left acromio-clavicular joint, MP: Mental protuberance, JN: Jugular notch, T1: First thoracic vertebra.

Figure 3. Experimental set up proposed and developed in this school-based protocol.

Figure 4. Jaw and cervical range of motion in the bruxism group before and after OMT or sham treatment at one week before and after the second treatment session. 


\section{Tables}

3 Table 1: Description of the Osteopathic Manipulative Treatment (OMT) and sham

\section{4 interventions (TIDieR-Placebo checklist)}

\begin{tabular}{|c|c|c|}
\hline & OMT & SHAM \\
\hline$W H Y$ & $\begin{array}{l}\text { Provide usual osteopathic care expected to } \\
\text { improve jaw and cervical mobility. }\end{array}$ & $\begin{array}{l}\text { Account for non-specific, contextual and natural effects } \\
\text { and isolate the OMT component of the treatment. }\end{array}$ \\
\hline PROCEDURES & $\begin{array}{l}\text { The session was personalized and included } \\
\text { patient history taking (past experience, } \\
\text { present state), physical examination, } \\
\text { diagnostic osteopathic assessment, OMT, } \\
\text { counselling, lifestyle change. } \\
\text { Physical examination was done before and } \\
\text { after treatment and included observation, } \\
\text { global functional tests, pain provocation tests, } \\
\text { orientation tests and local regional mobility } \\
\text { assessment. Osteopaths were instructed to } \\
\text { specifically evaluate jaw, cervical and upper } \\
\text { thoracic motion. }\end{array}$ & $\begin{array}{l}\text { The session was personalized and included patient } \\
\text { history taking (past experience, present state), physical } \\
\text { examination, diagnostic osteopathic assessment, and two } \\
\text { sham procedures that mimicked OMT, counselling, } \\
\text { lifestyle change. } \\
\text { Physical examination was done before and after sham } \\
\text { treatment and included observation, global functional } \\
\text { tests, pain provocation tests, orientation tests and local } \\
\text { regional mobility assessment. Osteopaths were } \\
\text { instructed to specifically evaluate jaw, cervical and } \\
\text { upper thoracic motion. }\end{array}$ \\
\hline WHO PROVIDED & $\begin{array}{l}\text { Participants were randomly allocated to receiv } \\
\text { practitioners were educators with supervision } \\
\text { years of experience in practice. All osteopaths } r \\
\text { calibration on patient management. }\end{array}$ & $\begin{array}{l}\text { treatment from one of six experienced osteopaths. All } \\
\text { xperience within the school clinic. They had at least } 10 \\
\text { ceived the same training for the procedures. There was no }\end{array}$ \\
\hline HOW & $\begin{array}{l}\text { OMT was personalized for the patient by } \\
\text { combining a wide range of osteopathic } \\
\text { techniques "as usual" without receiving any } \\
\text { instructions on decision criteria. Patient } \\
\text { preferences were accounted for. OMT } \\
\text { included soft tissue, MET and articulatory } \\
\text { techniques, visceral and cranial techniques. } \\
\text { Level of patient participation was not } \\
\text { standardised across treatments. }\end{array}$ & $\begin{array}{l}\text { Osteopaths performed a predefined OMT technique on a } \\
\text { specific region without any intent to induce changes in } \\
\text { tissue mobility. } \\
\text { Sham treatments were administered at two occasions in } \\
\text { a random order. The sham treatment was the same for } \\
\text { all participants and consisted of: } \\
\text { (1) Palpation of cranial mobility / MET for an inferior } \\
\text { glenohumeral / Tissue technique of the } 4 \text { th Left rib. } \\
\text { (2) Palpation of lower thorax orifice mobility / Soft } \\
\text { tissue technique of zygomatic bones / MET on the right } \\
\text { 5th rib posterolateral. }\end{array}$ \\
\hline WHERE & \multicolumn{2}{|c|}{ School clinic } \\
\hline HOW MUCH & \multicolumn{2}{|c|}{ Two treatment sessions ( $45^{\prime}$ ) separated by one week } \\
\hline TAILORING & $\begin{array}{l}\text { The intervention was adapted and tailored to } \\
\text { each participant including anamnesis, tests } \\
\text { and treatment. Fidelity to protocol was } \\
\text { assessed by analysing the reported } \\
\text { interpretation and actions of osteopaths. }\end{array}$ & $\begin{array}{l}\text { The sham procedure was of two types described above. } \\
\text { Fidelity to protocol was assessed by analysing the } \\
\text { reported interpretation and actions of osteopaths. }\end{array}$ \\
\hline $\begin{array}{l}\text { MEASURING THE } \\
\text { SUCCESS OF } \\
\text { BLINDING }\end{array}$ & \multicolumn{2}{|c|}{$\begin{array}{l}\text { Fifteen days' follow-up, participants were asked whether they believed they were in the active or sham } \\
\text { group. }\end{array}$} \\
\hline
\end{tabular}


6 Table 2: Characteristics of participants of this study at baseline. * Student T-test 7

\begin{tabular}{|c|c|c|c|c|c|c|}
\hline & \multicolumn{3}{|c|}{ Group with bruxism } & \multicolumn{3}{|c|}{ Group without bruxism } \\
\hline & $\begin{array}{c}\text { OMT } \\
\mathrm{n}(\%) \mid \text { mean } \\
\text { (SD) }\end{array}$ & $\begin{array}{c}\text { Sham } \\
\mathrm{n}(\%) \mid \text { mean } \\
(\mathrm{SD})\end{array}$ & $\underset{*}{\text { p-value }}$ & $\begin{array}{c}\text { OMT } \\
\mathrm{n}(\%) \mid \text { mean } \\
(\mathrm{SD})\end{array}$ & $\begin{array}{c}\text { Sham } \\
\mathrm{n}(\%) \mid \text { mean } \\
(\mathrm{SD})\end{array}$ & $\underset{*}{\mathbf{p}-\text { value }}$ \\
\hline Population $(\mathrm{N}=46)$ & 13 & 10 & & 12 & 11 & \\
\hline Sex; female & $10(76.9 \%)$ & $8(80 \%)$ & & $8(66.7 \%)$ & $8(72.7 \%)$ & \\
\hline Age (years) & $21.2( \pm 2.0)$ & $21.0( \pm 1.6)$ & & $20.7( \pm 2.5)$ & $20.3( \pm 1.8)$ & \\
\hline Weight $(\mathrm{Kg})$ & $65.8( \pm 15.8)$ & $65.7( \pm 13.0)$ & & $63.4( \pm 6.4)$ & $62.9( \pm 9.6)$ & \\
\hline Height (cm) & $171.4( \pm 9.8)$ & $171.5( \pm 7.8)$ & & $168.2( \pm 8.6)$ & $167.2( \pm 9.5)$ & \\
\hline \multicolumn{7}{|l|}{ Promotions } \\
\hline 1st year student & $2(15.4 \%)$ & $2(20 \%)$ & & $4(33.3 \%)$ & $3(27.3 \%)$ & \\
\hline 2nd year student & $2(15.4 \%)$ & $4(40 \%)$ & & $1(8.3 \%)$ & $3(27.3 \%)$ & \\
\hline 3rd year student & $4(30.8 \%)$ & $1(10 \%)$ & & $1(8.3 \%)$ & $2(18.2 \%)$ & \\
\hline 4th year student & $5(38.5 \%)$ & $3(30 \%)$ & & $6(50 \%)$ & $3(27.3 \%)$ & \\
\hline
\end{tabular}

\section{Bruxism}

characteristics

Bruxism start (past years)

$$
\begin{array}{lcc}
\text { years }) & 6.9( \pm 5.6) & 4.8( \pm 4.7) \\
\text { Static bruxism } & 7(53.8 \%) & 6(60 \%) \\
\text { Dynamic bruxism } & 1(7.7 \%) & 0(0 \%) \\
\text { Mixed bruxism } & 5(38.5 \%) & 4(40 \%) \\
\text { Daytime bruxism } & 2(15.4 \%) & 0(0 \%) \\
\text { Nocturnal bruxism } & 3(23.1 \%) & 6(60 \%) \\
\text { D and N bruxism } & 8(61.5 \%) & 4(40 \%)
\end{array}
$$

\section{Dental Health}

Wisdom tooth

extraction

Other dental

extraction

$$
\begin{array}{cc}
10(76.9 \%) & 5(50 \%) \\
0(0 \%) & 4(40 \%)
\end{array}
$$

\section{$5(41.7 \%) \quad 2(18.2 \%)$}

$1(8.3 \%) \quad 1(9.1 \%)$

\section{Range of motion} (degrees)

Jaw lateral movement Jaw opening

Cervical side-bending 

13

Table 3: Gain in jaw and cervical range of motion range from baseline in the group with bruxism at different time points. * Between group difference adjusted for baseline value with positive values representing increased range of motion for OMT group. $\uparrow$ Primary outcome

\begin{tabular}{|c|c|c|c|}
\hline & $\begin{array}{l}\text { OMT } \\
(\mathbf{n}=\mathbf{1 3}) \\
\text { mean }(\mathrm{SD})\end{array}$ & $\begin{array}{l}\text { Sham } \\
(\mathbf{n}=\mathbf{1 0}) \\
\text { mean }(\mathrm{SD})\end{array}$ & $\begin{array}{l}\text { Difference in changes from } \\
\text { baseline* } \\
\text { mean (CI95\%; p-value) }\end{array}$ \\
\hline \multicolumn{4}{|l|}{$\begin{array}{l}\text { Immediately after 1st session } \\
\text { (D0) }\end{array}$} \\
\hline $\begin{array}{l}\text { Jaw lateral movement } \\
\text { (degrees) }\end{array}$ & $25.5^{\circ}(4.0)$ & $23.6^{\circ}(5.4)$ & $3.4^{\circ}(1.0$ to $5.8 ; \mathrm{p}=0.007)$ \\
\hline Jaw opening (degrees) & $30.1^{\circ}(4.7)$ & $30.6^{\circ}(5.7)$ & $1.3^{\circ}(-0.7$ to $3.3 ; p=0.201)$ \\
\hline $\begin{array}{l}\text { Cervical side-bending } \\
\text { (degrees) }\end{array}$ & $72.9^{\circ}(9.5)$ & $73.9^{\circ}(8.2)$ & $5.2^{\circ}(0.1$ to $10.2 ; p=0.045)$ \\
\hline $\begin{array}{l}\text { Cervical rotation } \\
\text { (degrees) }\end{array}$ & $\begin{array}{l}128.2^{\circ} \\
(11.5)\end{array}$ & $\begin{array}{l}133.0^{\circ} \\
(11.4)\end{array}$ & $7.8^{\circ}(4.1$ to $11.5 ; \mathrm{p}<0.001)$ \\
\hline
\end{tabular}

Seven days after 1st session (D7) ${ }^{\dagger}$

Jaw lateral movement (degrees)

Jaw opening (degrees)

Cervical side-bending (degrees)

Cervical rotation (degrees) $25.9^{\circ}(4.2) \quad 24.1^{\circ}(5.6) \quad 3.3^{\circ}(0.6$ to $5.9 ; p=0.018)$

$31.8^{\circ}(5.6) \quad 31.0(6.0)$

$2.7^{\circ}(-0.02$ to $5.5 ; \mathrm{p}=0.052)$

$74.7(11.1) \quad 76.6(11.8) \quad 3.2^{\circ}(-0.8$ to $12.5 ; \mathrm{p}=0.080)$

134.7

(13.5)
135.5 $(12.5)$

\section{Immediately after 2nd session}

(D7)

\begin{tabular}{|c|c|c|c|}
\hline $\begin{array}{l}\text { Jaw lateral movement } \\
\text { (degrees) }\end{array}$ & $27.5^{\circ}(4.4)$ & $24.3^{\circ}(6.3)$ & $4.8^{\circ}(1.7$ to $8.0 ; p=0.005)$ \\
\hline Jaw opening (degrees) & $34.5^{\circ}(5.6)$ & $30.8^{\circ}(6.3)$ & $5.5^{\circ}(2.2$ to $8.7 ; p=0.002)$ \\
\hline $\begin{array}{l}\text { Cervical side-bending } \\
\text { (degrees) }\end{array}$ & $\begin{array}{l}76.9^{\circ} \\
(12.5)\end{array}$ & $\begin{array}{l}75.1^{\circ} \\
(11.0)\end{array}$ & $9.2^{\circ}(1.4$ to $17.0 ; p=0.023)$ \\
\hline $\begin{array}{l}\text { Cervical rotation } \\
\text { (degrees) }\end{array}$ & $\begin{array}{l}139.6^{\circ} \\
(14.7)\end{array}$ & $\begin{array}{l}135.9^{\circ} \\
(15.1)\end{array}$ & $18.2^{\circ}(9.8$ to $26.6 ; p<0.001$ \\
\hline
\end{tabular}




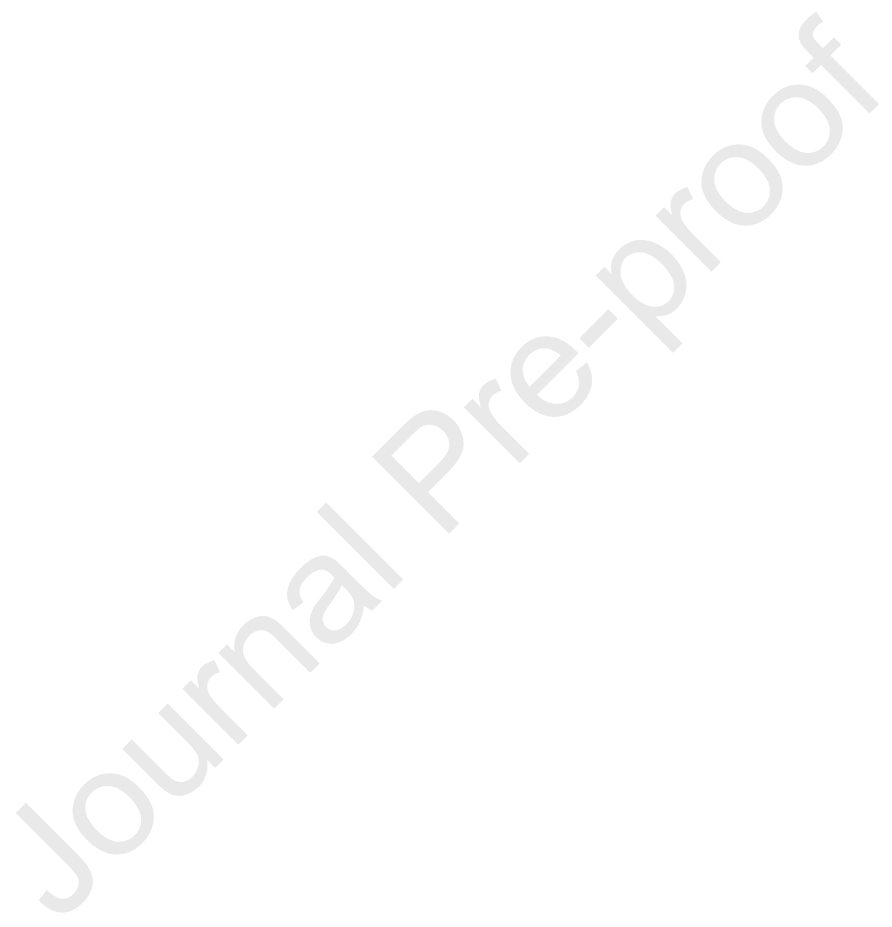



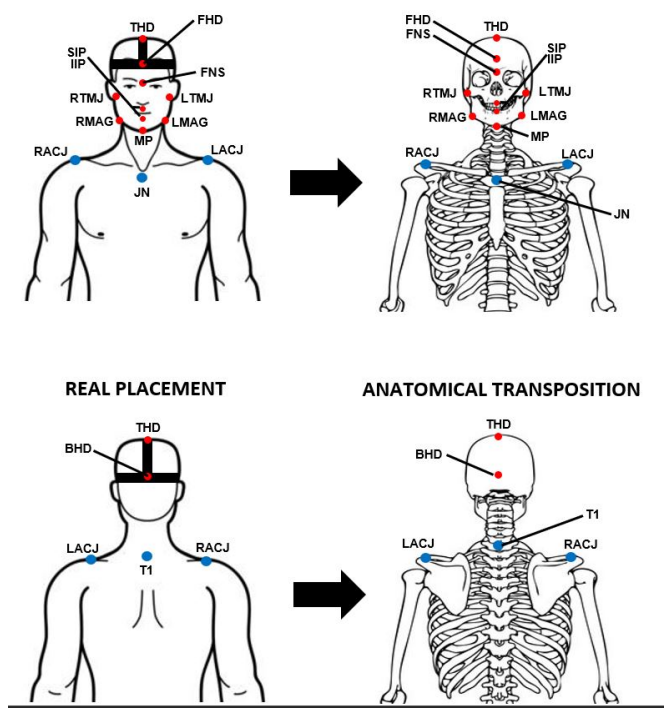


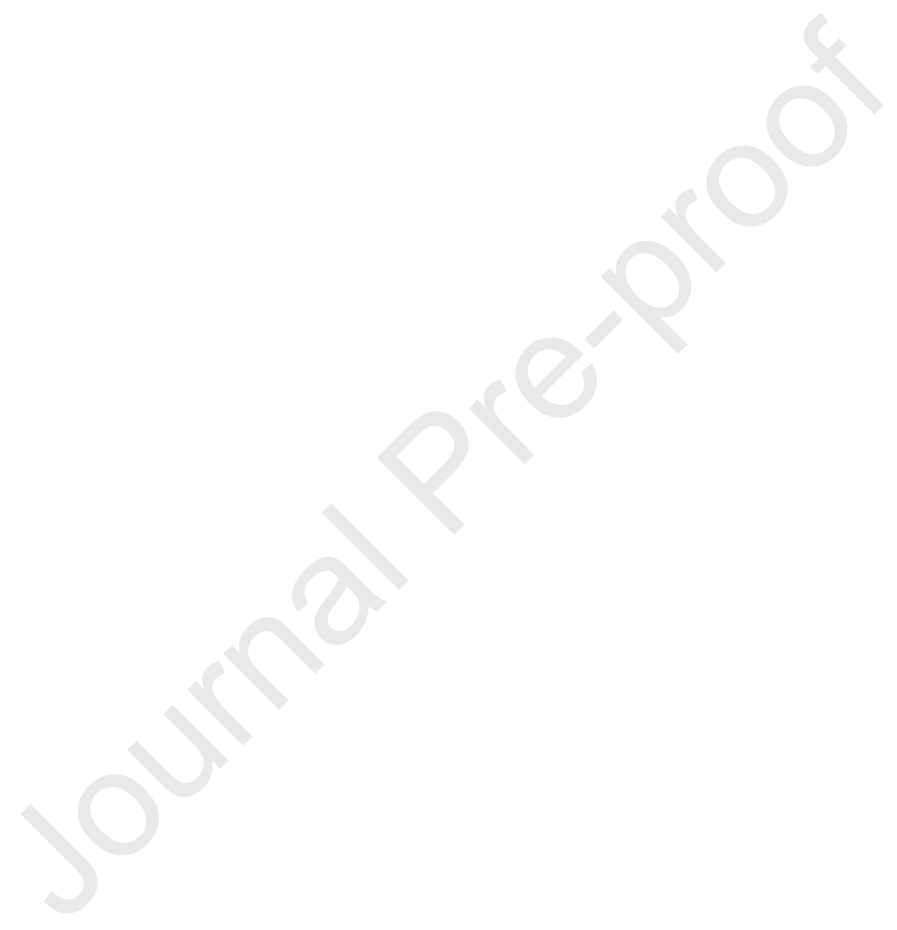




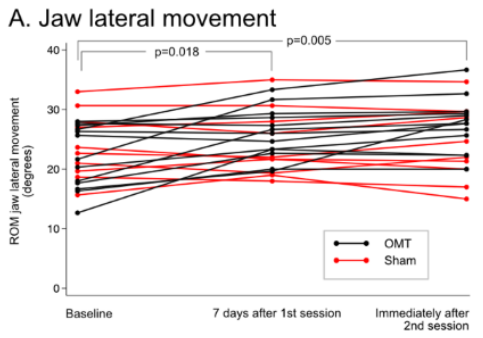

B. Jaw opening
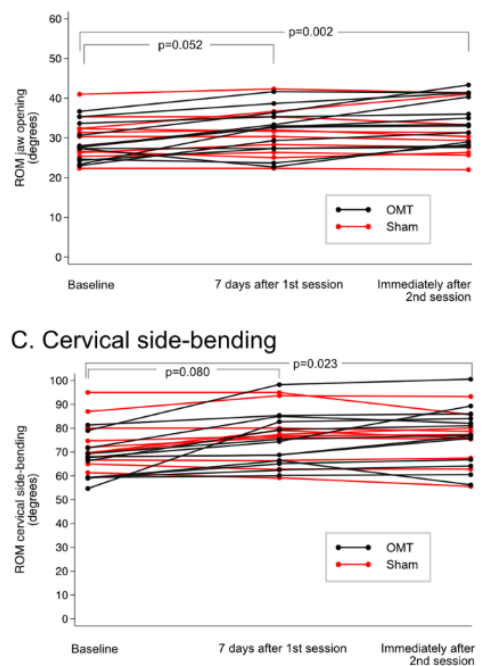

C. Cervical rotation

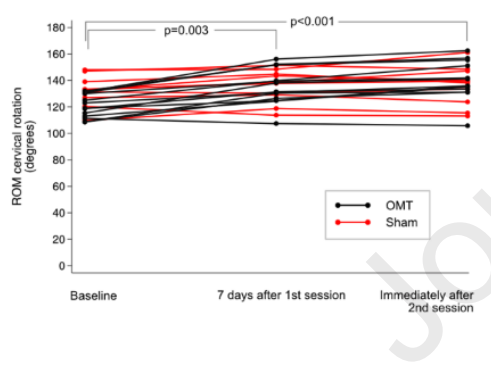




\section{CONFLICT OF INTEREST FILE}

(1) Conflict of Interest - none

\section{(2) Funding Sources}

This research did not receive any specific grant from funding agencies in the public, commercial, or not-for-profit sectors. Research staff were institution employees and a Master student. All costs related to the study were covered by the "Institut d'Ostéopathie de Rennes - Bretagne" except for the time spent by PV for statistical analysis and helping with writing the manuscript which were financed by the HES University of Applied Sciences and Arts Western Switzerland. Volunteers were not remunerated for their participations. The funders had no role in the study design, data collection and analysis, decision to publish, or preparation of the manuscript. The authors declare that they have no conflicts of interest.

(3) Ethical approval details (if applicable) - not applicable

\section{(4) Acknowledgments}

We acknowledge thank all students for their enthusiastic participation. We gratefully acknowledge Franck Sutre (DO), Florence Delauriere (DO, MSc), Alexis Guery (DO), Ludovic Lancelot (DO) and François Launay (DO) for their contribution to this study. The author also acknowledges Marylène Bourgin (DO, MM) and Emmanuel Harel (MM) for their logistic support during the two sessions of experimentation. 